ment fails in attaining its object. In such cases we would strongly urge that the mastoid cells should be trephined, and all caseous matter (which will probably be found) cleared out, and a thorough drainage of the tympanum established. By this method the presence of matter likely to form a focus of secondary infection would be avoided, a return to the local condition of health made possible, and the chances of subsequent intracranial suppuration considerably reduced.

\section{CLINICAL REMARKS ON}

\section{A CASE OF MALIGNANT OR PERNICIOUS ANAMIA IN WHICH A CONDITION OF CHRONIC GENERAL OSTEOMYELITIS WAS FOUND AFTER DEATH.}

\section{BY THOMAS H. KNOTT,} Fleet Surgeon, Royal Navy.

[Communicated by the Director-General of the Mirdical Department, Royal Naty.]

H. W. C., aged 24, able seaman, of fair general physique, came on the sick list February 16th, complaining of slight and ill-defined pains about his chest, epigastrium, and loins. He said he had been in failing health for three or four weeks; he had lost flesh, and was easily fatigued. On referring to his medical history sheet I find he had pleurisy in 1881, remittent fever in the East Indies in 1884, and an attack of purpura with dyspepsia in 1886.

After careful examination by myself and my colleague, Surgeon A. W. May, we could find nothing wrong. He had a clean tongue, fair appetite, and normal temperature, and all the bodily functions appeared to be regularly performed; his urine was acid and slightly phosphatic. As he looked anxious and ill, he was placed in bed for observation on a restricted diet.

There was, on the following day, considerable tenderness in the epigastric and hepatic regions; the liver was not enlarged, and no tumour could be detected; the respiratory murmur was weak on the right side; the sternal half of the right clavicle was much thickened; this he attributed to a fall from a horse three years previously; heart sounds normal.

Three days after admission he began to lose appetite, and vomit after food; he complained of much lumbar pain, and when he coughed or drew a deep inspiration, the pains in his chest and back were much increased. The epigastric and hepatic regions, if anything, became more tender ; there was no sign of jaundice. Four days later he began to romit almost incessantly: the vomited matters consisted of liquid, having a bitter taste, and of the colour of yolk of egg. After three days the bilious vomit became of a green colour. He was rapidly losing flesh; bowels became obstinately confined; tongue thickly coated and whitish no rise in temperature, and no localised tenderness in any of the bones.

At the end of ten days he was sent to the General Hospital at Auckland, as we were about to proceed to sea. In hospital he steadily lost ground, and became very weak and thin. There was much tenderness about the chest walls, and for two or three days some slight swelling was noticed over the sternum, but this disappeared entirely. He then had several attacks of epistaxis, and when I saw him, three weeks after admission to hospital, he looked like a man dying of pernicious anmmia. The bowels were very much constipated; he could take little or no food, as everything he tried to take caused disgust and nausea. His temperature one night was $100^{\circ} \mathrm{F}$., otherwise it had been normal or subnormal throughout. He died of exhaustion on the fortyfourth day.

Necropsy Eighteen Hours after Death.-Body extremely emaciated, skin of a white waxy colour. Abdomen : organs extremely pale and bloodless; all the fat had been absorbed; intestines contained small scybalous frecs throughout; liver small, structure healthy; kidneys and adrenals extremely pale but normal in structure. Stomach : a hard thickened patch was felt near the pylorus; the glands in the lesser curvature were of quite cartilaginous hardness, varying from a pea to a horse-bean in size pancreas and spleen healthy. On opening the stomach, the hard spot near the pylorus was found to be the cicatrix of an old ulcer, the size of a crown piece; the base was quite hard, resembling the glands at the lesser curvature. The blood ressels were healthy, but contained only pink serum. Chest: when the soft parts were turned back the periosteum and cartilages looked normal, but on dividing the ribs many of them were quite soft; the mal, but on dividing the ribs many of them were quite by a pink cancellous tissue The sternum was in the same condition, as were also the clavicles and femors, the periosteum being in all healthy. also the clavicles and femore, the periosteum being in all healthy. right apex. Heart and large vessels normal, but contained only serum.

This was a most puzzling case. During life he had been examined by all the medical staff, none of whom could form a satisfactory diagnosis. The extensive bone disease was not suspected, and might have been easily overlooked had not one of the ribs and might have been easidy at a bony part whilst dividing the been unintentionally divided at a bony part whilst dividing the of the areneral osteomyelitis, of which there was no indication until the bones were divided. My own idea of the case is that the chronic osteomyelitis was the initial disease, and that the anæmia was a direct result of the bone disease. If this view be the correct was a direct result of the the theory that the red corpuscles of the blood are formed originally, or are in some way matured, in the marrow and cancellous tissue of bones.

\section{CASE OF POPLITEAL ANEURYSM: LIGATURE OF FEMORAL ARTERY.}

BY FleEt-SuRgeon J. N. STONE, R.N.

[Communicated by the Director-Generat of the Medical DRPaRTMENT, Royal Nayy.]

W. L., aged 33, A.D. of II.M.S. T'éméraire, Mediterranean Station, while at sail drill aloft, on August 20th last, slipped in the rigging and immediately felt something give way behind the left knee. He reported himself to the medical officer on the following day, when a pulsating tumour was discovered in the popliteal space. Patient was sent to England for treatment, bed, bandages, and elevation of the limb being employed provisionally.

On arrival at Plymouth IIospital on September 18th he was found to have a pulsating tumour three inches long filling up the left popliteal space; a distinct bruit was present. Digital presleft popliteal space; a duccesion of volunteers was employed for twenty-four hours continuously, Signoroni's tourniquet being then substituted for a couple of hours, when digital pressure was again resorted to for a further period of twenty hours. This was well borne, but considerable œdema of leg and thigh resulted with but little diminution of pulsation. All pressure was for the present discarded. On the sulsidence of odema the tourniquet was again employed for several days with negative result.

Having regard to the size of the tumour and the presence of a loud rough bruit, treatment by Esmarch's bandage was not considered advisable, and it was accordingly decided to ligature the femoral. This was done antiseptically on 0ctober 8th, the vessel bsing deligated at Scarpa's angle. Kangaroo tendon was used, a small drainage tube entered, and the incision closed by three carbolised gut sutures, the whole dressed antiseptically. The limb was wrapped in cotton wadding and warmth applied to the foot.

October 9 th. Temperature $98.4^{\circ}$; pulse 80 . Very slight pain in shin; temperature of foot normal. 8 P.M., temperature $99.8^{\circ}$.

October 10 th. Temperature $98.4^{\circ}$; pulse 76 . Very little uneasiness in leg.

October 11 th. Temperature $98.4^{\circ}$; pulse normal. Quite comfortable: no pulsation in tumour since operation; no œdema of leg or foot; sensation unimpaired.

October 18th. Removed dressing for first time, ten days having elapsed; wound appears to have absolutely healed by first intention, ligature and sutures being absorbed, and drainage tube, which was thrown out, found dry in dressings. Tumour in popliteal space quite solidifed and about half original size.

November 6th. Has continued without an untoward sign or symptom. Amount of daily exercise gradually increased. Tumour quite solidified and reduced to about ono-sixth of original size. Use of limb seems perfect. Discharged to duty.

The main interest connected with this case appears to turn on the fact that the somewhat protracted course of pressure, digital and instrumental, prior to ligature, so far from exercising any untoward effect on the subsequent operation, appears to have had a 